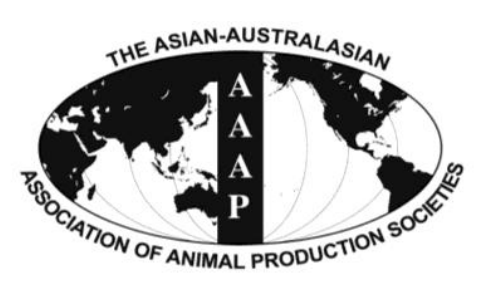

Open Access

Asian Australas. J. Anim. Sci.

Vol. 27, No. 8 : 1196-1203 August 2014

http://dx.doi.org/10.5713/ajas.2013.13394

www.ajas.info

pISSN 1011-2367 elSSN 1976-5517

\title{
Comparison of Aviary, Barn and Conventional Cage Raising of Chickens on Laying Performance and Egg Quality
}

\author{
M. Ahammed, B. J. Chae, J. Lohakare, B. Keohavong, M. H. Lee, S. J. Lee, \\ D. M. Kim, J. Y. Lee ${ }^{1}$, and S. J. Ohh* \\ College of Animal Life Sciences, Kangwon National University, Chuncheon 200-701, Korea
}

\begin{abstract}
This study intended to compare the productive performance of three different layer raising systems; conventional cage (CC), barn (BR) and aviary (AV). The AV is welfare bestowed housing that allows free locomotion for birds within the BR. The BR allows bird's free locomotion inside BR but without multilevel structures. Both pullets and cockerels were housed together in both AV and BR, but only pullets in CC. Seventeen weeks old Lohmann Brown Lite $(n=800)$ pullets were housed in AV during this study. The same age layer pullets were simultaneously assigned to either at CC or BR to compare egg production performance with AV. The duration of experiment was 40 weeks (from 21st to 60th week). There were no remarkable differences in egg production, hen day egg production (HDEP) and average egg weight among three rearing systems. First 20 weeks (phase-1) average HDEP (\%) of AV, CC, and BR were $85.9,88.8,87.1$ and average egg weights $(\mathrm{g})$ were 57.5, 59.9, and 56.9 respectively. Those of the remaining 20 weeks (phase-2) were 87.1, 87.9, 85.5 and 64.2, 63.0 62.1, respectively. Daily feed intakes (122 g, $110 \mathrm{~g}, 125 \mathrm{~g}$ ); feed conversion ratio $(2.4,2.1,2.5)$ and daily egg mass $(53.9 \mathrm{~g}, 54.4 \mathrm{~g}, 52.8 \mathrm{~g})$ data from $\mathrm{AV}, \mathrm{CC}$, and BR were not influenced significantly by the respective raising systems. Daily feed intake of layers in both AV (124 g) and BR (127 g) tended to be higher than that in CC (113 g) during phase-2. Overall, exterior egg quality (dirty and cracked eggs) in both phases was superior in BR compared with AV and CC, whereas CC generated intermediate results. This study indicated that the HDEP per se in AV and BR were not significantly different from that in CC. The study implied that the facility depreciation cost for AV and cost for increased feed intake in AV compared to CC are believed to be critical to evaluate the cost effectiveness of egg production in AV. (Key Words: Chicken Welfare, Aviary System, Poultry Housing, Productive Performance, Egg Traits)
\end{abstract}

\section{INTRODUCTION}

Welfare bestowed raisings has appeared as one of the most challenging issue in the current egg industry. In countries where the most of egg production has attained using battery cages, their replacement with welfare bestowing alternative systems became unavoidable. Although implementation of chicken welfare has not intended a remarkable benefit on productive performance, farmers have been aware of the productivity and economic feasibility.

\footnotetext{
* Corresponding Author: Sang Jip Ohh. Tel: +82-33-250-8631, Fax: +82-33-255-5482, E-mail: sjohh@kangwon.ac.kr

${ }^{1}$ National Institute of Animal Science, Suwon, Korea.

Submitted Jul. 5, 2013; Accepted Sept. 16, 2013; Revised Nov. 21, 2013
}

However, there are only little data that had compared welfare bestowed production systems in terms of production performance. Different housing systems for laying hens certainly exerted considerable effects on performance and production traits such as egg weight, feed efficiency, daily feed consumption, and mortality (Suto et al., 1997). In general, non-cage system can be characterized with more space for hen that allows more locomotion of bird. It has been known that more locomotion of the hen indicates more energy expenditure that need to be supported by increasing feed intake. However, laying performance of chicken depend not only where the hens are kept but also many of other factors. Nest is one of the integral parts of non-cage system because birds usually prefer to lay egg in a nest-box (Reed, 1994). In this context, battery cage is considered to be the most serious anti-welfare system

Copyright @ 2014 by Asian-Australasian Journal of Animal Sciences This is an open-access article distributed under the terms of the Creative Commons Attribution Non-Commercial License (http://creativecommons.org/licenses/by-nc/3.0/), which permits unrestricted non-commercial use, distribution, and reproduction in any medium, provided the original work is properly cited. 
(Duncan, 1992) due to absence of the nest.

Egg quality also plays an important role in egg industry both for producers and consumers. Some shell quality characteristics such as shell strength and shell thickness have a great importance from an economic point of view, since broken eggs (6 to $8 \%$ ) are discarded, causing money loss (Coucke et al., 1999). Shell properties are crucial also for shelf life and safety of eggs and egg products (Reu de et al., 2005). At the same time albumen properties has an influence on the preservation performance of eggs and egg product quality. Although benefit of egg quality has not been a key point of the welfare bestowed system. Many controversies on egg quality already been established among the different systems of rearing. Some (Van Den Brand et al., 2004) believed that, distribution, retailing practices and product turnover may play a major role on egg quality rather than the housing system. A recent study of Schlatterer and Breithaupt (2006) found different xanthophyll composition of organic eggs from free range, barn (BR) and cage eggs. Therefore, this study was designed to compare the performance of layers raised at welfare bestowing system with that at conventional battery cage.

\section{MATERIALS AND METHODS}

\section{Layer housing system}

Three raising systems were compared in this study. Conventional battery layer cage (CC) was chosen as control. As welfare bestowing facilities, both welfare aviary (AV) and BR were selected. The characteristics and features of these three systems were compared as shown in Table 1. The experimental protocol was approved by Ethical Committee of Kangwon National University, Chuncheon, Korea.

\section{Experimental birds and diets}

A total of 800 brown pullets (Lohmann Brown lite) at 17 weeks of age, were used in AV system for this study. At the same time one CC layer farm (no. of layers 600) and one BR layer farm (no. of layers 200) were assigned to compare the laying performance with AV. Ten percent of male chicken (80 in AV and 20 in BR) were used with layers at the onset of experiment. In AV system, welfare facilities and environmental conditions were supplied to meet the guidelines of Royal Society for the Prevention of Cruelty to Animals (RSPCA, 2008). Facilities and environmental conditions for $\mathrm{CC}$ and $\mathrm{BR}$ systems were provided to meet the instructions of standard management guide of Lohmann Brown Lite.

A commercial layer diet (17\% crude protein and 2,770 $\mathrm{kcal} / \mathrm{kg} \mathrm{ME}$ ) was fed to the layers regardless of whole types of rearing system. Feed was supplied manually twice a day to the CC and BR birds and automatically five times per day to the AV chickens. Ingredients and chemical composition of basal diet are shown in Table 2.

\section{Measurement of laying performance and salmonella contamination}

The performance parameter such as hen day egg production (HDEP), average egg weight was recorded daily. Data were calculated weekly but expressed in table by two phases (from 21 to 40 and 41 to 60 wks). Feed conversion ratio (FCR) was determined by the ratio between egg weight and feed consumption. Daily broken and grosscracked eggs were examined and calculated together. Dirty eggs from different systems were observed daily and recorded on weekly basis. Dead birds were separated immediately and subjected to examine the causes of death. Crude analysis was performed primarily considering the market price of egg and feed cost.

To measure the Salmonella contamination of egg shell, 10 eggs from each system were collected two times at 40th wk and 60th wk of age. Litter materials were simultaneous collected to analyze salmonella contamination. Selenite cystine broth was used to isolate and xylose-lysinedesoxycholate (XLD) agar to culture the Salmonella from egg and litter sample.

\section{Egg quality analysis}

Twenty eggs were selected two times at 30th and 50th of age to evaluate egg quality characteristics. Sufficient

Table 1. Characteristics and features of three laying hen housing systems

\begin{tabular}{lccc}
\hline Characteristics & Aviary $(\mathrm{AV})$ & Barn (BR) & Conventional cage (CC) \\
\hline Space for chicken $\left(\mathrm{cm}^{2} / \mathrm{hen}\right)$ & 1,850 & 2,050 & 650 \\
Freedom of locomotion & Yes & Yes & Restricted \\
Nest & Yes & Yes & No \\
Laying floor & Synthetic lawn & Rice husk & Wire mesh \\
Perch & Yes & Yes & No \\
Sand & Yes & Yes & No \\
Floor bedding & Saw dust & Rice husk & No \\
Cockerel & Yes & Yes & Hen only \\
Egg collection system & Automatic belt & Manual collection & Automatic \\
Manure collection system & Moving belt & Manual & Manual
\end{tabular}


Table 2. Ingredients and chemical composition of basal diet

\begin{tabular}{lc}
\hline Ingredients & Basal diet (\%) \\
\hline Corn grain & 58.00 \\
Soybean meal & 18.45 \\
Corn gluten meal & 4.00 \\
Wheat bran & 3.00 \\
Gluten feed & 1.97 \\
Rapeseed meal & 3.00 \\
Animal fat & 0.93 \\
Lysine 78 powder & 0.03 \\
Methionine (100\%) & 0.06 \\
DCP & 1.10 \\
Choline (50\%) & 0.09 \\
Limestone-L & 8.98 \\
Salt & 0.24 \\
Vit-min mix (Layer)* & 0.12 \\
Natuphos & 0.03 \\
Total & 100 \\
Chemical analysis (\%) & \\
Dry matter (DM) & 87.06 \\
Crude protein (CP) & 17.00 \\
Crude fat & 3.35 \\
Crude fiber & 2.96 \\
Crude ash & 12.55 \\
Ca & 3.80 \\
Total P & 0.53 \\
Available P & 0.45 \\
Metabolizable energy (kcal/kg) & 2,770 \\
Lys & 0.80 \\
Met & 0.37 \\
\hline DCP, di-calcim &
\end{tabular}

DCP, di-calcium phosphate.

* Provided the following nutrients per kg of diet: Vit A 8,000 IU; Vit $\mathrm{D}_{3}$ 2,000 IU; Vit E 8 IU; Vit $\mathrm{K}_{3} 2 \mathrm{mg}$; $\mathrm{B}_{1} 1.5 \mathrm{mg} ; \mathrm{B}_{2} 5 \mathrm{mg}$; $\mathrm{B}_{6} 2.2 \mathrm{mg}$; $\mathrm{B}_{12}$ $0.02 \mathrm{mg}$; pantothenic acid $12 \mathrm{mg}$; niacin $30 \mathrm{mg}$; biotin $0.05 \mathrm{mg}$; folic acid $0.5 \mathrm{mg}$; Cu 6 mg; Iron $55 \mathrm{mg}$; Zn $55 \mathrm{mg}$; Mn $65 \mathrm{mg}$; I $0.5 \mathrm{mg}$; Se $0.2 \mathrm{mg}$.

numbers of eggs were collected from each raising system, then twenty eggs representing average weight and size of the system at that time were subjected for the egg quality analysis. All eggs were individually weighed. Width and length $(\mathrm{cm})$ of each egg were measured using a manual calipers and shape index was calculated as percent ratio between egg width and egg length. Shell strength $\left(\mathrm{kg} / \mathrm{cm}^{2}\right)$ of non-cracked eggs was measured using HANDPI Digital Force Gauge (Model HANDPI-HLD-Taipei, Taiwan). Shell thickness meter was used to determine the shell thickness (mm) of egg.

Albumen height, Haugh unit (HU) and yolk color were considered as the parameters of internal egg quality. Albumen height $(\mathrm{mm})$ was measured by using stage micrometer manually. And based on albumen height, HU was calculated using the equation proposed by Haugh (Stadelman, 1995). Yolk color was evaluated on 20 individual yolks by comparison with the Roche fan (DSM, 2005-HMB, 51548, Basel, Switzerland).

\section{Statistical analysis}

Only for egg quality parameters, statistical analyses were performed with one-way ANOVA, using PROC general linear model procedure of SAS, (version 9.1, 2004, SAS Institute Inc., Cary, NC) with treatment group as sources of variation. All statements of significance were based on a probability value of equal to or less than 0.05 . Duncan's multiple range tests was used to separate group means. For performance parameters, the data was not statistically analyzed as there were no replicate pens.

\section{RESULTS}

\section{Egg production and egg mass}

Table 3 shows the summary of the egg production performance under three rearing systems. The HDEP data were similar among three systems and there was no remarkable difference in performance between two phases of production period. However, HDEP was slightly higher in CC birds in both phases compared to that in other systems. Egg mass data among different systems were almost similar and superior egg mass was observed in CC in the first 20 weeks. Variation of egg mass was more influenced by the age of hen rather than systems. Eggs laid by BR chickens after 40 weeks showed lower egg mass

Table 3. Production performance and feed consumption in Lohmann Brown Lite layers in three different rearing systems from 21 to 60 wks of age

\begin{tabular}{|c|c|c|c|c|c|c|}
\hline \multirow[t]{2}{*}{ Parameters } & \multicolumn{2}{|c|}{$\begin{array}{c}\text { Aviary (AV) } \\
n=800\end{array}$} & \multicolumn{2}{|c|}{$\begin{array}{c}\text { Barn (BR) } \\
n=200\end{array}$} & \multicolumn{2}{|c|}{$\begin{array}{c}\text { Conventional cage (CC) } \\
n=600\end{array}$} \\
\hline & 21 to $40 \mathrm{wks}$ & 41 to $60 \mathrm{wks}$ & 21 to $40 \mathrm{wks}$ & 41 to $60 \mathrm{wks}$ & 21 to $40 \mathrm{wks}$ & 41 to $60 \mathrm{wks}$ \\
\hline$\overline{\operatorname{HDEP}(\%)}$ & 85.9 & 87.1 & 87.1 & 85.5 & 88.8 & 87.9 \\
\hline Average egg wt (g) & 57.5 & 64.2 & 56.9 & 62.1 & 59.9 & 63.0 \\
\hline Daily feed intake (g/bird) & 122 & 124 & 125 & 127 & 110 & 113 \\
\hline FCR ( $g$ of feed:g of egg) & 2.40 & 2.52 & 2.53 & 2.71 & 2.17 & 2.21 \\
\hline Egg mass (g/d/bird) & 53.9 & 52.7 & 52.8 & 50.5 & 54.4 & 53.2 \\
\hline Mortality (\%) & 2.2 & 3.8 & 2.5 & 1.8 & 2.3 & 2.1 \\
\hline
\end{tabular}

$\mathrm{n}$, number of bird in the rearing system; HDEP, hen day egg production; FCR, feed conversion ratio. 
Table 4. Egg quality of eggs produced from layer in three different rearing systems from 21 to 40 wks of age

\begin{tabular}{|c|c|c|c|c|c|}
\hline Parameters & Aviary (AV) & Barn (BR) & Conventional cage (CC) & SEM & p-value \\
\hline \multicolumn{6}{|l|}{ External quality } \\
\hline Shape index (\%) & 78.4 & 78.25 & 80.35 & 1.35 & NS \\
\hline Breaking strength $\left(\mathrm{kg} / \mathrm{cm}^{2}\right)$ & $3.89^{\mathrm{a}}$ & $3.12^{\mathrm{b}}$ & $2.95^{\mathrm{c}}$ & 0.056 & 0.001 \\
\hline Shell thickness (mm) & 0.39 & 0.40 & 0.38 & 0.017 & NS \\
\hline Shell color score & 12.7 & 10.3 & 11.2 & 0.272 & NS \\
\hline Dirty eggs (\%) & $2.9^{\mathrm{b}}$ & $1.6^{\mathrm{c}}$ & $3.8^{\mathrm{a}}$ & 0.067 & 0.001 \\
\hline Cracked and broken eggs (\%) & $2.5^{\mathrm{b}}$ & $1.3^{\mathrm{c}}$ & $3.9^{\mathrm{a}}$ & 0.039 & 0.001 \\
\hline \multicolumn{6}{|l|}{ Internal quality } \\
\hline Albumen height (mm) & $9.3^{\mathrm{b}}$ & $8.5^{\mathrm{c}}$ & $10.7^{\mathrm{a}}$ & 0.068 & 0.001 \\
\hline Haugh unit (HU) & $96.4^{\mathrm{ab}}$ & $92.7^{\mathrm{b}}$ & $102.2^{\mathrm{a}}$ & 2.172 & 0.039 \\
\hline Yolk color score & $6.4^{\mathrm{a}}$ & $4.5^{\mathrm{b}}$ & $4.8^{\mathrm{b}}$ & 0.138 & 0.001 \\
\hline
\end{tabular}

SEM, standard error of means; NS, not significant ( $p>0.05)$.

${ }^{a, b, c}$ Means in the same row with different superscript letters are significantly different at $\mathrm{p}<0.05$.

compared to AV and CC which was only $50.5 \mathrm{~g}$.

\section{Egg weight and feed conversion ratio}

There was no remarkable difference in average egg weight and FCR among rearing systems (Table 3). Egg weight in $\mathrm{CC}$ birds tended to be higher in the age 21 to 40 weeks but AV chicken showed the highest egg weight in phase-2 (41 to 60 weeks). Comparatively lower egg weight was observed from BR layers in both phases. As expected, egg weight increased with increasing age of hen. Egg weight increased substantially from production phase 1 to 2 followed by the progressive maturity of production. FCR value was also similar among different systems, although better FCR (2.17) was found in CC birds and poor FCR (2.71) was found in BR birds. Average feed intake among the chicken of different systems greatly differed. Barn chicken consumed higher (125 g) amount of feed compared to $\mathrm{CC}(110 \mathrm{~g})$ chickens in phase-1 (Figure 2). In phase-2 the same tendency of feed consumption was also observed for all groups of chickens.

\section{Egg quality}

Table 4 and 5 represents the external and internal characteristics of egg in both phases. External egg quality such as shape index, shell thickness and shell color score were not observed any significant $(p>0.05)$ differences among rearing systems in phase-1 but shell strength in case of AV eggs was significantly $(\mathrm{p}<0.05)$ higher $\left(3.89 \mathrm{~kg} / \mathrm{cm}^{2}\right)$ than that of CC $\left(2.95 \mathrm{~kg} / \mathrm{cm}^{2}\right)$ and BR $\left(3.12 \mathrm{~kg} / \mathrm{cm}^{2}\right)$. Shell thickness was significantly $(\mathrm{p}<0.05)$ higher in AV $(0.42$ $\mathrm{mm})$ and $\mathrm{BR}(0.41 \mathrm{~mm})$ eggs compared to $\mathrm{CC}$ eggs $(0.37$ $\mathrm{mm}$ ) in phase-2. Rearing system was also significantly $(p<0.05)$ affected the overall percentage of cracked and broken eggs in both phases. Higher incidence of cracked eggs $(4.5 \%)$ was recorded from $\mathrm{AV}$ in phase-2 compared to eggs from BR $(1.7 \%)$ and CC $(3.2 \%)$ hens. The number of cracked and broken eggs was increased with increasing days in lay (Table 5) in both AV and BR systems. Although, in phase-1, cracked eggs (3.9\%) from CC was higher but this trend tended to be reduced (3.2\%) in phase-2. More dirty eggs $(3.8 \%$ and $3.7 \%)$ were obtained by CC system compared to others, whereas it was intermediate $(2.9 \%$ and

Table 5. Egg quality of eggs produced from layers in three different rearing systems from 41 to 60 wks of age

\begin{tabular}{|c|c|c|c|c|c|}
\hline Parameters & Aviary (AV) & Barn (BR) & Conventional cage (CC) & SEM & p-value \\
\hline \multicolumn{6}{|l|}{ External quality } \\
\hline Shape index $(\%)$ & 78.16 & 77.39 & 76.88 & 0.383 & NS \\
\hline Breaking strength $\left(\mathrm{kg} / \mathrm{cm}^{2}\right)$ & 3.46 & 3.28 & 3.02 & 0.492 & NS \\
\hline Shell thickness (mm) & $0.42^{\mathrm{a}}$ & $0.41^{\mathrm{a}}$ & $0.37^{\mathrm{b}}$ & 0.017 & 0.017 \\
\hline Shell color score & 9.7 & 8.6 & 10.3 & 0.437 & NS \\
\hline Dirty eggs (\%) & $3.3^{\mathrm{b}}$ & $2.2^{\mathrm{c}}$ & $3.7^{\mathrm{a}}$ & 0.049 & 0.001 \\
\hline Cracked and broken eggs (\%) & $4.5^{\mathrm{b}}$ & $1.7^{\mathrm{c}}$ & $3.2^{\mathrm{a}}$ & 0.067 & 0.001 \\
\hline \multicolumn{6}{|l|}{ Internal quality } \\
\hline Albumen height (mm) & $7.4^{\mathrm{b}}$ & $6.9^{\mathrm{c}}$ & $9.2^{\mathrm{a}}$ & 0.038 & 0.001 \\
\hline Haugh unit (HU) & $86.5^{\mathrm{b}}$ & $81.1^{\mathrm{b}}$ & $94.8^{\mathrm{a}}$ & 1.858 & 0.003 \\
\hline Yolk color score & 8.8 & 8.0 & 8.2 & 0.367 & NS \\
\hline
\end{tabular}

SEM, standard error of means; NS, not significant ( $p>0.05)$.

${ }_{a, b, c}$ Means in the same row with different superscript letters are significantly different at $\mathrm{p}<0.05$. 
Table 6. Cost comparison among different rearing systems

\begin{tabular}{lccc}
\hline Parameters & Aviary $(\mathrm{AV})$ & Barn $(\mathrm{BR})$ & Conventional cage $(\mathrm{CC})$ \\
\hline Feed cost $(\$ / 10$ eggs)* & $0.78(113)$ & $0.87(126)$ & $0.69(100)$ \\
Sales price $(\$ / 10$ eggs)* & $3.0(167)$ & $2.5(139)$ & $1.8(100)$ \\
\hline
\end{tabular}

* Feed and egg price were adjusted according to the price of local market.

() is showing relation index referring to the value of $\mathrm{CC}$ as 100 .

\section{$3.3 \%$ ) in AV system.}

Internal quality parameters of egg were significantly influenced by the rearing systems in both phases. The eggs of the hen kept in the CC system had the significantly $(\mathrm{p}<0.05)$ greater albumen height $(10.7 \mathrm{~mm})$ and HU value (102.2) compared to $\mathrm{AV}$ (9.3 mm and 96.4) and BR (8.5 $\mathrm{mm}$ and 92.7) eggs in phase-1. Albumen height and HU value were also found the similar trend in phase-2. Almost similar yolk color was found among the eggs of different systems in phase-2 but yolk color was significantly better in AV eggs (6.4) compared to eggs from BR (4.5) and CC (4.8) layers in phase-1 (Table 4).

\section{Mortality}

According to the postmortem observations of dead birds, feather pecking was recorded the most likely cause of death. In comparison among rearing systems, little variation was found in percentage of mortality. Although the mortality was numerically higher in phase-2 of AV (3.8\%) compared to $\mathrm{CC}(2.1 \%)$ and BR $(1.8 \%)$ but no symptoms of disease or parasites were found. Mortality increased from phase 1 to 2 in $\mathrm{AV}$ but decreased in $\mathrm{CC}$ and BR.

\section{Salmonella contamination}

No Salmonella contamination was found from the microbiological analysis of eggs and litters regardless of the rearing system. It indicates that the rearing environment and surroundings of farms had no previous contamination of Salmonella. Therefore, this study could not compare the characteristics of salmonella contamination due to difference in rearing system.

\section{Economic evaluation}

Table 6 represented the result of crude level cost comparison among systems. It showed that the price of AV eggs was higher than that of others. Relation index was used to consider the comparison of eggs sales price among systems. Relation index value of CC considered as 100 for egg sales price whether it was 167 and 139 for AV and BR respectively. But the variation of feed cost per 10 eggs was small when compared between cage and non-cage systems (Table 6).

\section{DISCUSSION}

Raising chicken in AV system has been considered the new possibility of chicken welfare. Present study was designed to observe the laying performance of chicken under AV system and compare with that of other conventional systems. This study showed that egg production performance of modern layers was not significantly affected by the rearing systems (Figure 1). Some studies (Abrahamsson et al., 1996; Tauson et al., 1999) have reported that egg production of laying hens was higher in CC than those housed in alternative systems such as aviaries, floor pens, or free range. Comparatively lower egg mass was found from BR in phase-2 (41 to 60 weeks). During this period egg production from BR layers was also

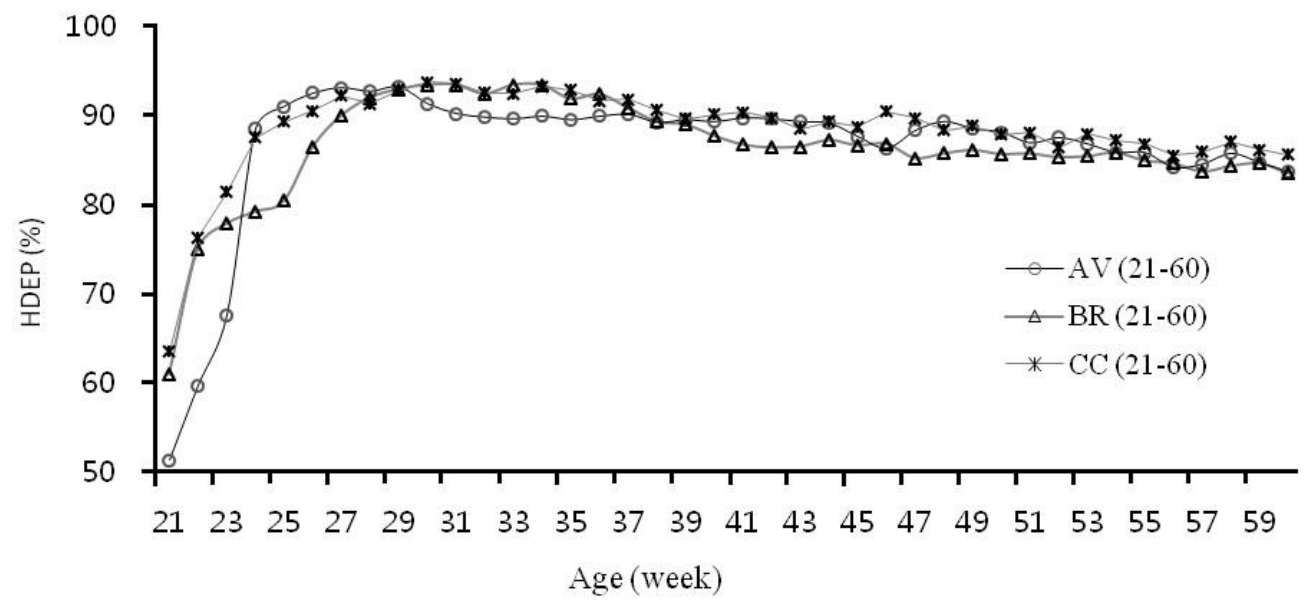

Figure 1. Comparison of HDEP (\%) of layer chicken under different rearing systems. HDEP, hen day egg production; AV, aviary; BR, barn; CC, conventional cage. 
poor. Dukic-Stojcic et al. (2009) found significantly greater egg mass in $\mathrm{CC}$ compared to the eggs from BR which was is similar to our results. Better egg mass from $\mathrm{CC}$ birds due to both HDEP and egg weight were highest in this group. This view can be found form Yakabu et al. (2007) who observed that eggs from conventional cages were larger than those from floor pens. Although in contrast to the findings of Vits et al. (2005) who reported greater egg weights in floor pens than in CC.

In both phases non-caged birds showed the poor FCR than caged birds. This poor FCR is believed to be associated with lowest amount of feed intake by the same bird. Due to locomotion activities, the amount of feed consumption by non-caged (BR and AV) layer was comparatively higher than that of caged layer (Figure 2). Data showed that the daily feed consumption per bird per day was $124 \mathrm{~g}$ and $127 \mathrm{~g}$ in phase-2 of non-caged birds whereas it was only $113 \mathrm{~g}$ in caged birds. This was in the line with the findings of Preisinger (2000), who reported that birds in non-caged system tended to eat more feed compared to $\mathrm{CC}$ to provide energy for heat production to compensate for the lower heat. Results from previous study (Emmans and Charles, 1977) have indicated that higher stocking densities in $\mathrm{CC}$ hen have been associated with ease of maintaining temperature within the optimal range, resulting in lower feed consumption. However, Tactacan et al. (2009) found no variation in feed consumption between $\mathrm{CC}$ and enriched cages.

The mortality percent of hen was slightly higher in AV than in CC and BR. This is in contrast with Abrahamsson and Tauson (1995), who found that mortality can be low in alternative housing systems such as AV, BR or free range. However, mortality is influenced by several factors and it is difficult to classify the real causes according to housing systems. Another study from Tauson et al. (1999) found overall greater mortality of Lohmann Brown hens in floor pens than in cages, largely related to feather pecking, with no difference between housing systems. In most cases of dead birds, feather pecking was observed in AV system. The greater space available for hens housed in the AV and BR increased the opportunity for birds to flap their wings. The higher number of birds housed in AV in this study may have increased the possibility of feather pecking and also cannibalism. A higher incidence of cannibalism in non-cage housing systems compared with $\mathrm{CC}$ was also reported previously by Fossum et al. (2009). Although, pullets with intact beaks was housed in the AV due to welfare concern, but the mortality was within the normal range for modern layer. Several studies (Weitzenbürger et al., 2005; Guesdon et al., 2006) reported that cannibalism is also a problem in caged layers. In this study, relatively lower percentage of mortality observed since beak-trimmed birds were employed. Guesdon et al. (2006) compared beak-trimmed and no beak-trimmed birds in conventional and enriched cages and found low mortality $(<5 \%)$ in beak-trimmed hens compared to no beak-trimmed hens $(>40 \%)$.

The overall percent of dirty eggs, gross cracked and broken eggs were also affected by the systems. It has been shown from the present study that the higher number of eggs laid outside the nest in AV likely affected proportion of cracked eggs and similar result also reported from furnished cage by Wall (2011). An egg laid outside the nest was at a high risk of damage due to the locomotion activities of hens in AV and FH systems. Present study indicated the superior result about egg quality in BR, because comparatively little number of eggs found outside the nest and eggs were not damaged by locomotion of birds. The amount of dirty eggs in $\mathrm{AV}$ was intermediate but in $\mathrm{CC}$ it was two times higher than those laid in BR. Higher number of dirty eggs in CC can be attributed to lay and droppings at the same region of the cage that mixed with excreta and resulting in dirty eggs. Mallet et al. (2006) showed that the proportion of dirty eggs

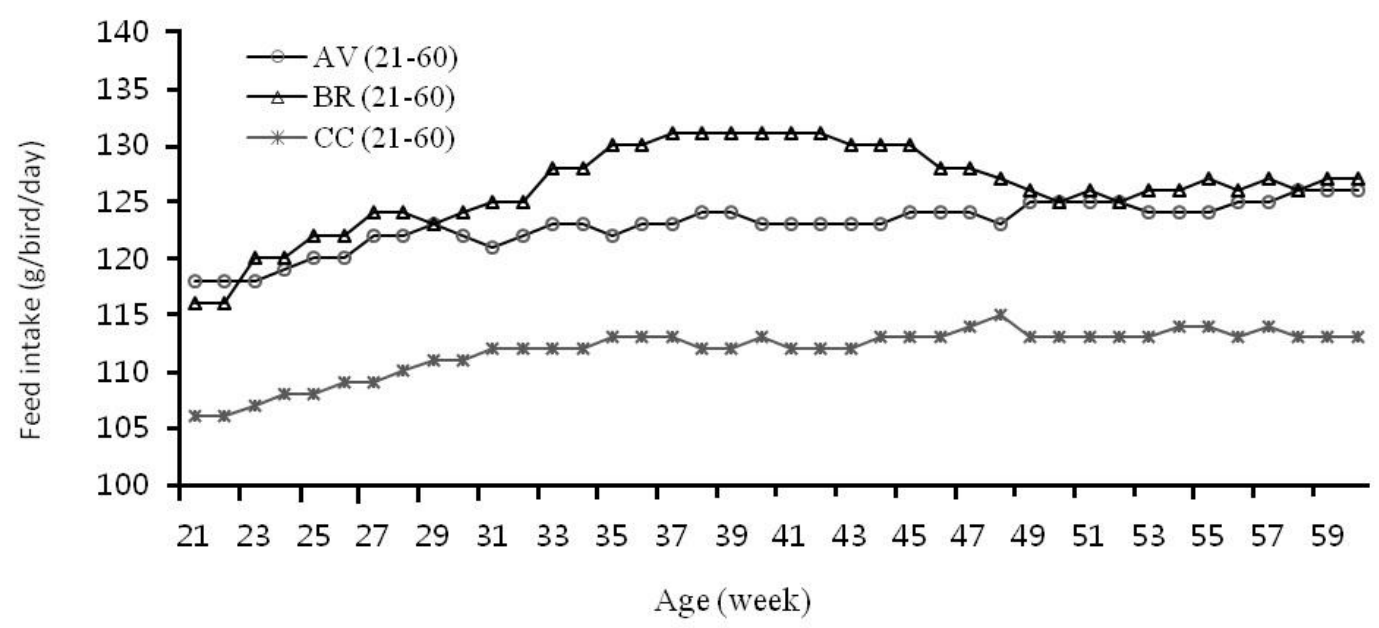

Figure 2. Comparison of feed intake (g/bird/day) of layer chicken under different rearing systems. AV, aviary; BR, barn; CC, conventional cage. 
was lower among eggs laid in a nest than among eggs laid on the litter or in the cage area. Tactacan et al. (2009) also found similar problem with high proportion of dirty eggs laid outside the nest compared to nest eggs in non-cage system.

Present study showed that the housing system did not affect the shell color and shape index of eggs and this was similar to the findings of Dukic-Stojcic et al. (2009). Shell thickness was lowest in $\mathrm{CC}$, while $\mathrm{AV}$ and $\mathrm{BR}$ eggs represented the highest values. A number of other studies (Pavlovski et al., 2001; Hidalgo et al., 2008) have observed thicker shell in BR eggs and lowest shell thickness registered for $\mathrm{CC}$ eggs. On the other hand, Tumova and Ebeid (2003) noticed thicker shell in CC compared to BR. But Taylor and Hurnik (1996) didn't find differences between $\mathrm{CC}$ and BR systems in shell thichness. Lower average egg size and better shell strength were observed in both $\mathrm{AV}$ and BR eggs where birds were allowed for free movement. This result might be explained by the study of Casiraghi et al. (2005) who pointed out an indirect correlation of egg size and shell strength. Thinner shell as those measured for CC eggs in the present study have been shown to have a direct correlation with shell strength. Poor shell strength resulted for thinner shell in CC eggs.

Average $\mathrm{HU}$ and albumen height of $\mathrm{CC}$ eggs was significantly better than AV and BR in both phases. Singh et al. (2009) found lower albumen height in eggs from BR than CC system, which was also the case in present research. In floor pen (BR), lower albumen height of eggs may be due to their exposure to ammonia (from litter) which affects albumen quality (Roberts, 2004). The AV system allowed free locomotion with multi-level structure for hens and provided litter only on floor that might have resulted minimum exposure to ammonia. Better HU was obtained from AV eggs compared to BR. Pavlovski et al. (1989) also found greater albumen height and $\mathrm{HU}$ from $\mathrm{CC}$ eggs when compared with BR eggs. Yolk color was greater for eggs from AV than others in phase-1. But in phase-2 almost similar score was found from all systems. However, the main contributing factor for yolk color is the diet (Lesson and Summers, 1991), although all chicken were fed the same diet in present research. This could be the dilution effect of greater egg production and variation in the rate of lay among hens in phase-1. Pistekova et al. (2006) found greater yolk color in $\mathrm{BR}$ than in $\mathrm{CC}$, but provided no potential reason for the difference. Singh et al. (2009) observed differences in the yolk color at different ages among strains in the floor pen.

Cost of feed as well as other costs such as labor, pullets, and housing facility are known to be higher with non-cage system. However, the present study only considered the current market price of egg and feed cost in the local market.
The cost of feed per unit of egg among different housing systems was not significantly different (Table 6). But egg price varied significantly between cage and non-cage sources.

\section{CONCLUSIONS}

Based on the result of this study, it could be said that the egg production rate was not seriously influenced by the rearing systems. However, daily feed intake by both AV and $\mathrm{BR}$ hen was higher than hen in CC as it was expected due to more locomotion activity by hen in AV and BR. Although there were differences among rearing systems in some egg quality parameters, the differences were incoherent and not be logically explained. From the economic point of view, higher production cost of non-cage eggs was primarily due to higher feed intake. Considering the premium price for the welfare bestowed eggs, AV can be satisfactorily employed as the welfare bestowing rearing system for commercial scale farm. Further research is needed to optimize the feed intake at the welfare AV.

\section{REFERENCES}

Abrahamsson, P. and R. Tauson. 1995. Aviary systems and conventional cages for laying hens: Effects on production, egg quality, health and birds' location in three hybrids. Acta Agric. Scand. A Anim. Sci. 45:191-203.

Abrahamsson, P., R. Tauson, and K. Elwinger. 1996. Effect on production, health and egg quality of varying proportions of wheat and barley in diets for two hybrids of laying hens kept in different housing systems. Acta Agric. Scand. 46:173-182.

Casiraghi, E., A. Hidalgo, and M. Rossi. 2005. Influence of weight grade on shell characteristics of marketed hen eggs. In Proceedings of the 10th European symposium on the quality of eggs and egg products (pp. 183-188). Doorwerth: WPSA.

Coucke, P., E. Dewil, E. Decuypere, and J. De Baerdemaeker. 1999. Measuring the mechanical stiffness of an eggshell using resonant frequency analysis. Br. Poult. Sci. 40:227-232.

Dukic-Stojcic, M., L. Peric, S. Bjedov, and N. Milosevic. 2009. The quality of table eggs produced in different housing systems. Biotech. Anim. Husbandry 25:1103-1108.

Duncan, I. J. H. 1992. Guest editorial: Designing environments for animals - Not for public perceptions. Br. Vet. J. 148:475-477.

Fossum, O., D. S. Jansson, P. E. Etterlin, and I. Vagsholm. 2009. Causes of mortality in laying hens in different housing systems in 2001 to 2004. Acta Vet. Scand. 51:3.

Guesdon, V., A. M. H. Ahmed, S. Mallet, J. M. Faure, and Y. Nys. 2006. Effects of beak trimming and cage design on laying hen performance and egg quality. Br. Poult. Sci. 47:1-12.

Hidalgo, A., M. Rossi, F. Clerici, and S. Ratti. 2008. A market study on the quality characteristics of eggs from different housing systems. Food Chem. 106:1031-1038.

Lesson, S. and J. D. Summers. 1991. Commercial poultry nutrition. University Books. Guelph. Ontario. Canada. 
Mallet, S., V. Guesdon, A. M. H. Ahmed, and Y. Nys. 2006. Comparison of eggshell hygiene in two housing systems: Standard and furnished cages. Br. Poult. Sci. 47:30-35.

Pavlovski, Z., D. Cunja, and B. Mašić. 1989. Kvalitet jaja kokoši držanih u različitim sistemima proizvodnje. Peradarstvo 1112:344-345.

Pavlovski, Z., S. Hopic, and M. Lukic. 2001. Housing system for layers and egg quality. Biotech. Anim. Husb. 17:197-201.

Pistekova, V., M. Hovorka, V. Vecerek, E. Strakova, and P. Suchy. 2006. The quality comparison of egg laid by laying hens kept in battery cages and in a deep litter system. Czech J. Anim. Sci. 51:318-325.

Preisinger, R. 2000. Lohmann tradition, praxiserfahrung und entwicklungsperspektiven. Lohmann Inform. 3:13-16.

Reed, H. J. 1994. Designing a nest for a battery cage. Pages 27-34 in Modified Cages for Laying Hens (Ed. C. M. Sherwin). Universities Federation for Animal Welfare, Potters Bar, UK.

Reu, K. De, K. Grijspeerdt, M. Heyndrickx, J. Zoons, K. Baere, De, M. Uyttendaele, J. Debevere, and L. Herman. 2005. Bacterial eggshell contamination in conventional cages, furnished cages and aviary housing systems for laying hens. Br. Poult. Sci. 46:149-155.

Roberts, J. R. 2004. Factors affecting egg internal quality and egg shell quality in laying hens. J. Poult. Sci. 41:161-177.

RSPCA (The Royal Society for the Prevention of Cruelty to Animals). 2008. UK`s leading animal welfare charity. www.rspca.org.uk/sciencegroup.

SAS Institute. 2004. SAS/STAT user's guide. Version 9.1. SAS Institute Inc, Cary, NC.

Schlatterer, J. and D. Breithaupt. 2006. Xanthophylls in commercial egg yolks: Quantification and identification by HPLC and LC-(APCI) MS using a C30 phase. J. Agric. Food Chem. 54:2267-2273.

Singh, R., K. M. Cheng, and F. G. Silversides. 2009. Production performance and egg quality of four strains of laying hens kept in conventional cages and floor pens. Poult. Sci. 88:256-264.
Stadelman, W. J. 1995. Quality identification of shell eggs. In: Egg science and technology (Ed. W. J. Stadelman and O. J. Cotterill) (pp. 39-66). New York: Food Products Press, The Haworth Press, Inc.

Suto, Z., P. Horn, and J. Ujvari. 1997. The effect of different housing systems on production and egg quality traits of brown and Leghorn type layers. Acta Agraria Kaposvariensis 1:29-35.

Tactacan, G. B., W. Guenter, N. J. Lewis, J. C. RodriguezLecompte, and J. D. House. 2009. Performance and welfare of laying hens in conventional and enriched cages. Poult. Sci. 88:698-707.

Tauson, R., A. Wahlstrom, and P. Abrahamsson. 1999. Effect of two floor housing systems and cages on health, production, and fear response in layers. J. Appl. Poult. Res. 8:152-159.

Taylor, A. A. and J. F. Hurnik. 1996. The long-term productivity of hens housed in battery cages and aviary. Poult. Sci. 75:47-51.

Tumova, E. and T. Ebeid. 2003. Effect of housing system on performance and egg quality characteristics in laying hens. Scientia Agriculturae Bohemica. 34:73-80.

Van Den Brand, H., H. K. Parmentier, and B. Kemp. 2004. Effects of housing system (outdoor vs cages) and age of laying hens on egg characteristics. Br. Poult. Sci. 45:745-752.

Vits, A., D. Weizenburger, H. Hamann, and O. Distl. 2005. Influence of different small group systems on production traits, egg quality and bone breaking strength of laying hens. First communication: Production traits and egg quality. Zuchtungskunde 77:303-323.

Wall, H. 2011. Production performance and proportion of nest eggs in layer hybrids housed in different designs of furnished cages. Poult. Sci. 90:2153-2161.

Weitzenbürger, D., A. Vits, H. Hamann, and O. Distl. 2005. Effect of furnished small group housing systems and furnished cages on mortality and causes of death in two layer strains. Br. Poult. Sci. 46:553-559.

Yakabu, A., A. E. Salako, and A. O. Ige. 2007. Effect of genotype and housing system on the laying performance of chickens in different seasons in semi-humid tropics. Int. J. Poult. Sci. 6:434-439. 